EDITORIAL

\title{
La relación médico-paciente
}

\author{
The patient - physician relationship
}

Un tema un tanto olvidado en la formación médica en los últimos años es la relación médico-paciente. En la antigüedad esta relación constituía la base del éxito del ejercicio de la práctica médica. Se trata de esa relación humana que surge de una necesidad de atención del que padece un problema de salud y que se establece con otro ser humano quien ha desarrollado vocacionalmente las competencias para atender y aliviar esos padecimientos.

La relación médico-paciente, casi siempre vertical por una supuesta superioridad de conocimiento, puede en nuestros tiempos haber perdido la connotación humana y es que la frivolidad que ha cobrado la medicina gracias al incentivo comercial, en donde el medico pierde su visión de benevolencia en la relación para convertirla en una relación de prestador de servicio al cliente informado. Este último, ya con una mayor cantidad de información obtenida a través de redes y plataformas informáticas, se ha convertido en un fuerte cuestionador de su prescriptor. Este cliente informado ha recibido por esta misma red no solo información inducida sobre sus posibles diagnósticos y tratamientos, pero también recibe elementos para exigir al prestador de salud lo que esta información inducida le dice que es el tratamiento correcto.

Es indudable que el negocio de la industria farmacéutica es uno de los más lucrativos hoy en día. Estas compañías invierten grandes sumas de dinero, ya no solo en investigación de nuevas moléculas sino también en estudios de mercado, y lograr que los clientes exijan esos maravillosos tratamientos que ofrecen curarlos de lo que las redes les vendieron como padecimiento. Es decir, nos enferman de lo que necesitan vender. La pérdida del sentido humano del acto médico nos ha llevado al extremo de creer que constituye atención medica un simple mensaje de texto 0 una llamada telefónica a un call center, en el cual se puede narrar los síntomas a un interlocutor al otro lado de la línea. A través de este proceso el paciente recibe lo que realmente importa en una relación comercial: generar una venta. Todo esto sin tener la certeza de si quien lo atendió era un médico y si está acreditado con las competencias necesarias para brindar una atención segura.

Hay dos conceptos fundamentales que han cambiado: la creciente y excesiva autonomía del paciente y la contrastante pérdida de autonomía del médico, quien se ha convertido prácticamente en esclavo de aquellos que encontraron en la medicina una oportunidad brillante de hacer negocios. Estos comerciantes juegan con el dolor del que padece y esclavizan al profesional de la medicina quien deberá, si quiere ser competitivo en el difícil mercado laboral, saber mediar entre la atención vocacional y la rentabilidad de la empresa o red prestadora que lo contrata. $Y$ nos preguntamos: ¿En qué momento el Estado abandonó la garantía del derecho a la salud? ¿En qué momento la más humana de la ciencia dejó de ser el arte de aliviar el dolor del que sufre?

Considero que es urgente reflexionar sobre lo que estamos haciendo. Asimismo, hacer lo necesario para recuperar y exigir la garantía plena del derecho a la salud justamente como derecho humano universal, sin restricciones, con calidad, pero sobre todo con calidez. La calidez de la relación que merece el ser humano que sufre y que se establece con un ser humano que desarrolló la vocacional y compasiva misión de aliviar el sufrimiento de quien lo padece. Nada es más satisfactorio para el desarrollo integral de una persona que la conciencia y autonomía del ejercicio digno de lo que decidió ser como profesional. Esto no tiene precio y debe recuperarse a toda costa.

\author{
Dra. Suyapa M. Figueroa \\ Presidenta \\ Colegio Médico de Honduras
}

